\title{
METAL BODY ARMOUR: BIOMIMETIC ENGINEERING OF LATTICE STRUCTURES
}

\section{A. du Plessis ${ }^{1 *}$, C. Broeckhoven ${ }^{2}$}

\begin{abstract}
Biomimicry in additive manufacturing often refers to topology optimization and the use of lattice structures, due to the organic shape of the topology-optimized designs, and the lattices often looking similar to many light-weight structures found in nature such as trabecular bone, wood, sponges, coral, to name a few. Real biomimetic design however involves the use of design principles taken in some way from natural systems. In this work we use a methodology whereby high resolution $3 \mathrm{D}$ analysis of a natural material with desirable properties is "reverse-engineered" and the design tested for the purpose. This allows more accurate replication of the desired properties, and adaption of the design parameters to the material used for production (which usually differs from the biological material). One such example is the impact-protective natural design of the glyptodont body armour. In this paper we report on the production of body armour models in metal (Ti4Al4V) and analyze the resulting mechanical properties, assessing their potential for impact protective applications. This is the first biomimetic study using metal additive manufacturing to date.
\end{abstract}

Keywords: Biomimicry; biomimetic engineering; energy absorption; lattice structure; additive manufacturing; powder bed fusion; X-ray tomography; microCT; non-destructive testing; 3D image analysis

1* Department of Physics, University of Stellenbosch, South Africa (Corresponding author, email: anton2@sun.ac.za)

${ }^{2}$ Functional Morphology Lab, University of Antwerp, Belgium

Presented at the 19th Annual International RAPDASA conference, held from 7 to 9 November 2018 in Johannesburg, South Africa. 


\section{INTRODUCTION}

Biomimicry refers to the discipline that studies nature's best ideas (i.e. biological structures and mechanisms) and consequently imitates these in an attempt to solve engineering problems [1]. The term is often used in the context of additive manufacturing, when design is done using topology optimization techniques and when lattice structures are used, often with no real biological imitation in mind. The reference to biomimicry in this case is due to the organic or "bionic" shape of the resulting topology-optimized designs, and the lattices often looking similar to many light-weight structures found in nature - such as trabecular bone, wood, sponges, coral, to name a few.

Topology optimization and the use of lattices is a fast growing field of design for additive manufacturing and a very promising avenue for new applications of the technology. The complexity of design allowed by additive manufacturing can be fully exploited in these designs, making light-weighting, tailored stiffness, and many new material designs possible in a variety of materials. The state of the art in topology optimization based design is reviewed in [2].

Besides organic shapes and biologically-plausible lattices, real biomimetic design may be incorporated into the design process (even as part of a topology optimization workflow), as is suggested in [3]. In this proposed workflow, the design engineer makes use of a biological database for bio-inspiration ideas or inputs in the design process. For example, when light-weight structures with good flexural properties are required, wood or bamboo design parameters are used. This latter work moves closer towards real mimicry of natural structures.

An even more detailed biomimetic approach is to analyze the detailed structural information of a natural system which has some desirable property, and use this information to reverse-engineer simplified structures for engineering applications. The design parameters of the model structures can be varied and simulations performed or physical models tested to analyze the performance of the models for the application in mind. This is the process used in [4], where a specific biological structure was analyzed in great detail, reverse-engineered simplified models generated with some design variations, and its performance analyzed for energy absorption and hence impact-protection applications. In this work, the natural body armour was analyzed for energy absorption and hence impact protection using high resolution microCT, reverse engineering of simplified models, simulation and mechanical testing of polymer models produced by laser sintering.

The analysis technique used in this work is X-ray micro computed tomography (microCT), which is widely used for detailed 3D analysis of biological structures, see for example [5,6]. As analysis technique it is especially useful to analyze the inner structural details of samples, such as the lattice or foam core parameters in a natural light-weight system. The resulting strut thickness distributions can be used as inputs in a traditional design process, for replicating similar models, with more regular lattice designs suitable for engineering structures.

The body armour of the glyptodont, an extinct mammal related to modern-day armadillos, is the focus of the biomimetic design in this work. The reason for this particular body armour is due to its unique impact protective role - these animals are known to have been involved in intraspecific conflict involving tailclub blows, making its body armour crucially important. It was previously shown that the body armour of lizards might have multiple competing functions, such as thermoregulation and protection, depending on environmental and ecological conditions as shown in [7]. However, a physiological role of body armour is expected to be relatively unimportant in glyptodonts given their taxonomic position (i.e., ability to regulate body temperature metabolically). Therefore we assume that the main function of body armour in glyptodonts was protection as described in more detail in [4].

In this previous work a series of simplified models based on the natural body armour unit was designed, using a combination of a solid shell and lattice core. This type of system is already well known as impact protective material in general, especially for metal foams $[8,9]$, but the use of an additive manufactured system for this purpose was not investigated prior to our knowledge. The biomimetic design values are varied and the obtained mechanical properties reported, which provides insight into the use of this design for impact protective devices using additive manufacturing. In contrast to previously reported results based on laser sintered plastic samples, this work focusses on metal body armour units (Ti6Al4V). In addition to the reported properties of the first biomimetic impact protective metal samples to date, the produced samples are analysed by microCT showing impressive quality even for thin struts, making the results applicable for other work using lattice designs. 


\section{MATERIALS AND METHODS}

The glyptodont body armour comprises of adjoining hexagonal units called osteoderms - bony plates embedded in the skin. A selected glyptodont (Glyptotherium sp.) osteoderm was scanned by high resolution microCT using the hardware described in [10] and the morphological analysis including strut thickness and density was reported previously, as was the design of the reverse engineered simplified model [4]. Briefly, the osteoderm size and shape was replicated ( $28 \mathrm{~mm}$ diameter hexagonal shape, $12 \mathrm{~mm}$ high), with the "solid" cortical bone modelled as a solid shell of $1 \mathrm{~mm}$ and the internal foam core (trabecular bone) modelled as regular "diagonal" lattice. The lattice-shell combinations were created in Materialize Magics, with varying design parameters according to the specifications in Table 1. As shown here, the parameters investigated where the unit cell size, the lattice porosity and the shell thickness. The variation of the unit cell size of the lattice varies only the strut thickness but not the total density. Besides the lattice strut thickness, porosity and shell thickness, a model with no internal lattice and only shell was produced for comparison.

Table 1: Design parameters for samples tested in this work

\begin{tabular}{|l|c|c|c|c|}
\hline \multicolumn{1}{|c|}{$\begin{array}{c}\text { Sample } \\
\text { description }\end{array}$} & Shell & $\begin{array}{c}\text { Unit cell } \\
\text { size, mm }\end{array}$ & $\begin{array}{c}\text { Design } \\
\text { internal } \\
\text { lattice core } \\
\text { porosity }\end{array}$ & $\begin{array}{c}\text { Design strut } \\
\text { thickness }\end{array}$ \\
\hline $\begin{array}{l}\text { Reference reverse } \\
\text { engineered lattice }\end{array}$ & $1 \mathrm{~mm}$ & $3 \mathrm{~mm}$ & $80 \%$ & $0.6 \mathrm{~mm}$ \\
\hline $\begin{array}{l}\text { Sample 1: thinner } \\
\text { strut, same } \\
\text { density same }\end{array}$ & $1 \mathrm{~mm}$ & $1.5 \mathrm{~mm}$ & $80 \%$ & $0.3 \mathrm{~mm}$ \\
\hline $\begin{array}{l}\text { Sample 2: thicker } \\
\text { strut, } \\
\text { density }\end{array}$ & $1 \mathrm{~mm}$ & $5 \mathrm{~mm}$ & $80 \%$ & $1.0 \mathrm{~mm}$ \\
\hline $\begin{array}{l}\text { Sample 3: thicker } \\
\text { strut, same unit } \\
\text { cell size as } \\
\text { reference }\end{array}$ & $1 \mathrm{~mm}$ & $3 \mathrm{~mm}$ & $62 \%$ & $0.9 \mathrm{~mm}$ \\
\hline $\begin{array}{l}\text { Sample 4: thicker } \\
\text { strut, same unit } \\
\text { cell size as } \\
\text { reference }\end{array}$ & $1 \mathrm{~mm}$ & $3 \mathrm{~mm}$ & $43 \%$ & $1.2 \mathrm{~mm}$ \\
\hline $\begin{array}{l}\text { Sample 5: thicker } \\
\text { shell, no lattice } \\
\text { core (same total } \\
\text { density as } \\
\text { reference) }\end{array}$ & $1.5 \mathrm{~mm}$ & $3 \mathrm{~mm}$ & $100 \%$ & $0.3 \mathrm{~mm}$ \\
\hline $\begin{array}{l}\text { Sample 6: thinner } \\
\text { shell, thinner } \\
\text { struts } \\
\text { density } \\
\text { reference) }\end{array}$ & $0.5 \mathrm{~mm}$ & $3 \mathrm{~mm}$ & $74 \%$ & $0.8 \mathrm{~mm}$ \\
\hline $\begin{array}{l}\text { Sample 7: no shell } \\
\text { Same }\end{array}$ & $0 \mathrm{~mm}$ & $1.5 \mathrm{~mm}$ & $80 \%$ & \\
\hline
\end{tabular}

Ti6Al4V ELI samples were produced on an EOS M280 (200 W) machine using recommended process parameters for this material and $30 \mu \mathrm{m}$ layer thickness. Stress relief heat treatment after the build was done at $650{ }^{\circ} \mathrm{C}$ in Ar atmosphere for $3 \mathrm{hrs}$. Samples were removed from the build plate and washed in ultrasonic bath. Two of the produced samples are shown in Figure 1, with the shell versions having holes added to the top and bottom shells to allow unconsolidated powder to be removed. Three samples of each type were produced, one of each was subjected to mechanical compression test, and one of each subjected to microCT scans [11]. MicroCT scans showed no remaining powder inside the samples. 


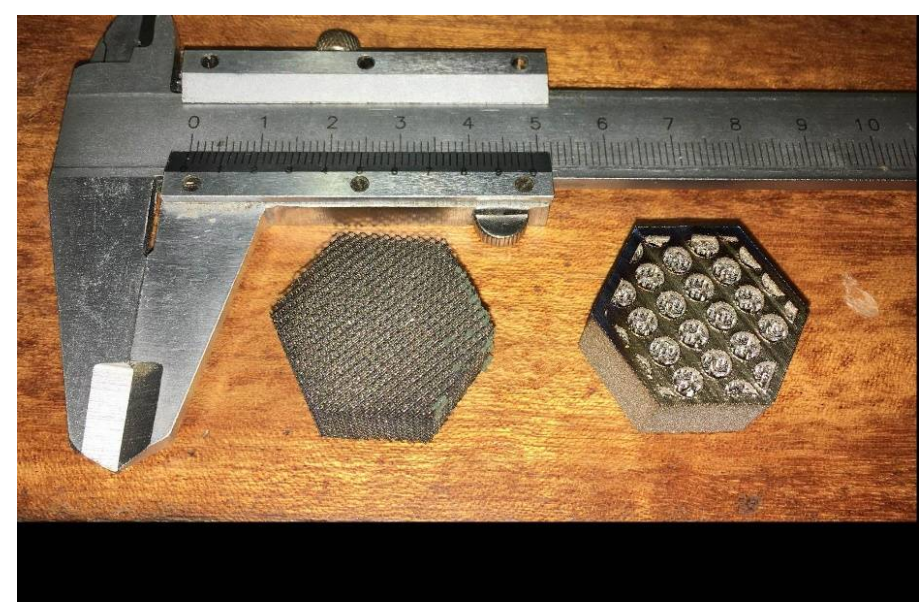

Figure 1: Two of the produced Ti6Al4V biomimetic samples - lattice-only model (left) and a lattice-shell combination (right).

Quasi-static compression tests were performed using an Amsler press with $250 \mathrm{kN}$ max and crosshead displacement measurement sensor attached. Energy absorption can be calculated from the stress-strain data as in [4,12]. In this work a qualitative assessment is made from the force-displacement curves, as all samples have the same geometry. The compressive strength of solid Ti6Al4V is expected to be roughly $900 \mathrm{MPa}$ [13]. 


\section{RESULTS AND DISCUSSION}

The lattice-only model (number 7 in Table 1) is used to demonstrate the microCT analysis as it is relatively easily visualised. Figure 2 shows microCT results of this actual produced sample, in cross-sectional and 3D views.
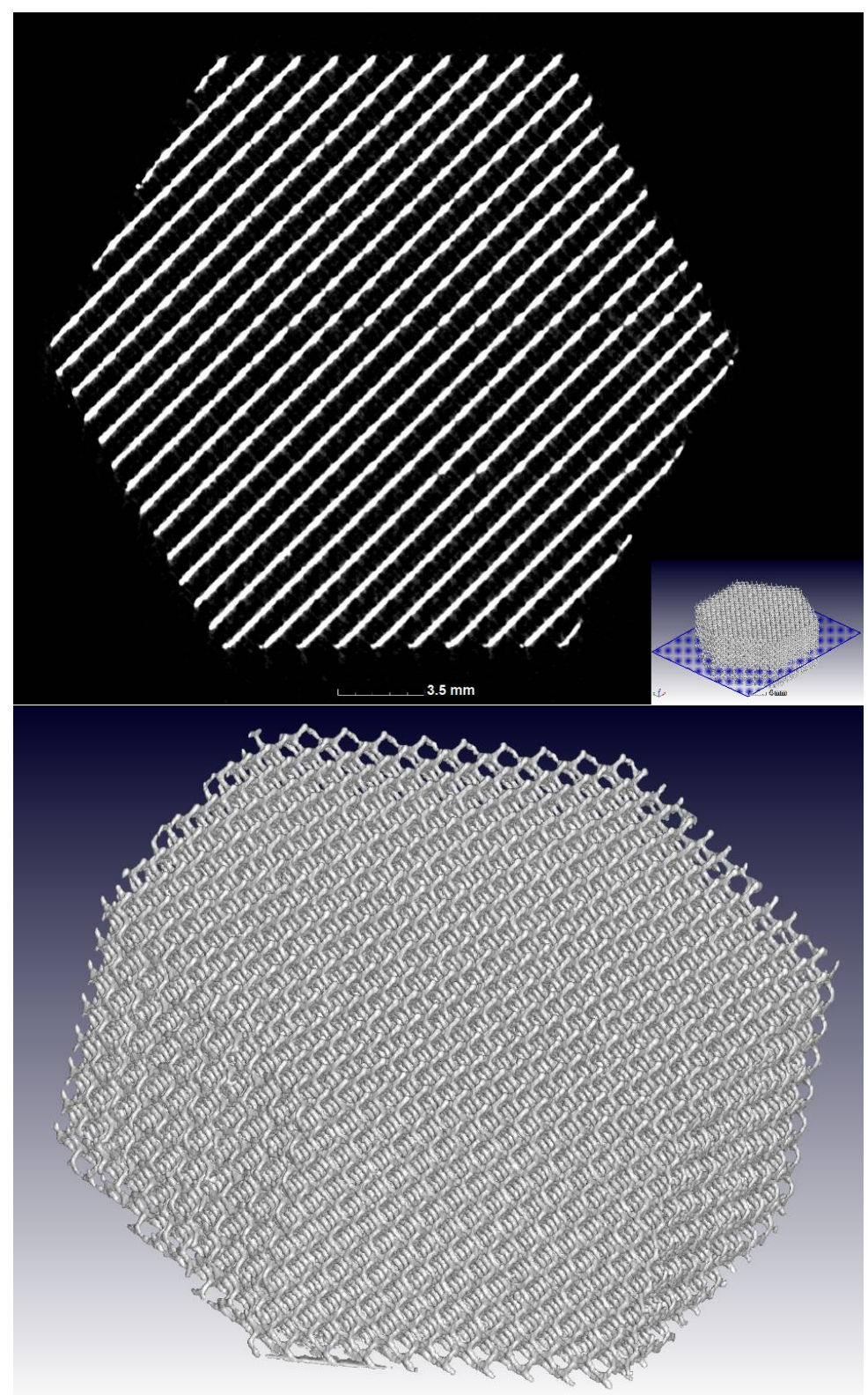

Figure 2: MicroCT images of produced sample with lattice-only design (sample number 7).

Subsequent detailed microCT data analysis of the produced parts demonstrate the successful production of diamond-lattice struts with mean diameter of $0.2 \mathrm{~mm}$ as shown in Figure 3 , which is excellent considering the single track width is only in the region of 0.1 to $0.15 \mathrm{~mm}$, depending on exact scanning parameters. The bimodal strut thickness shown is due to the strut junctions which are thicker than the struts themselves. Similar work was reported on the manufacturability of microlattices of the same material type using the same process parameters indicating smaller strut thickness can be achieved [14]. 

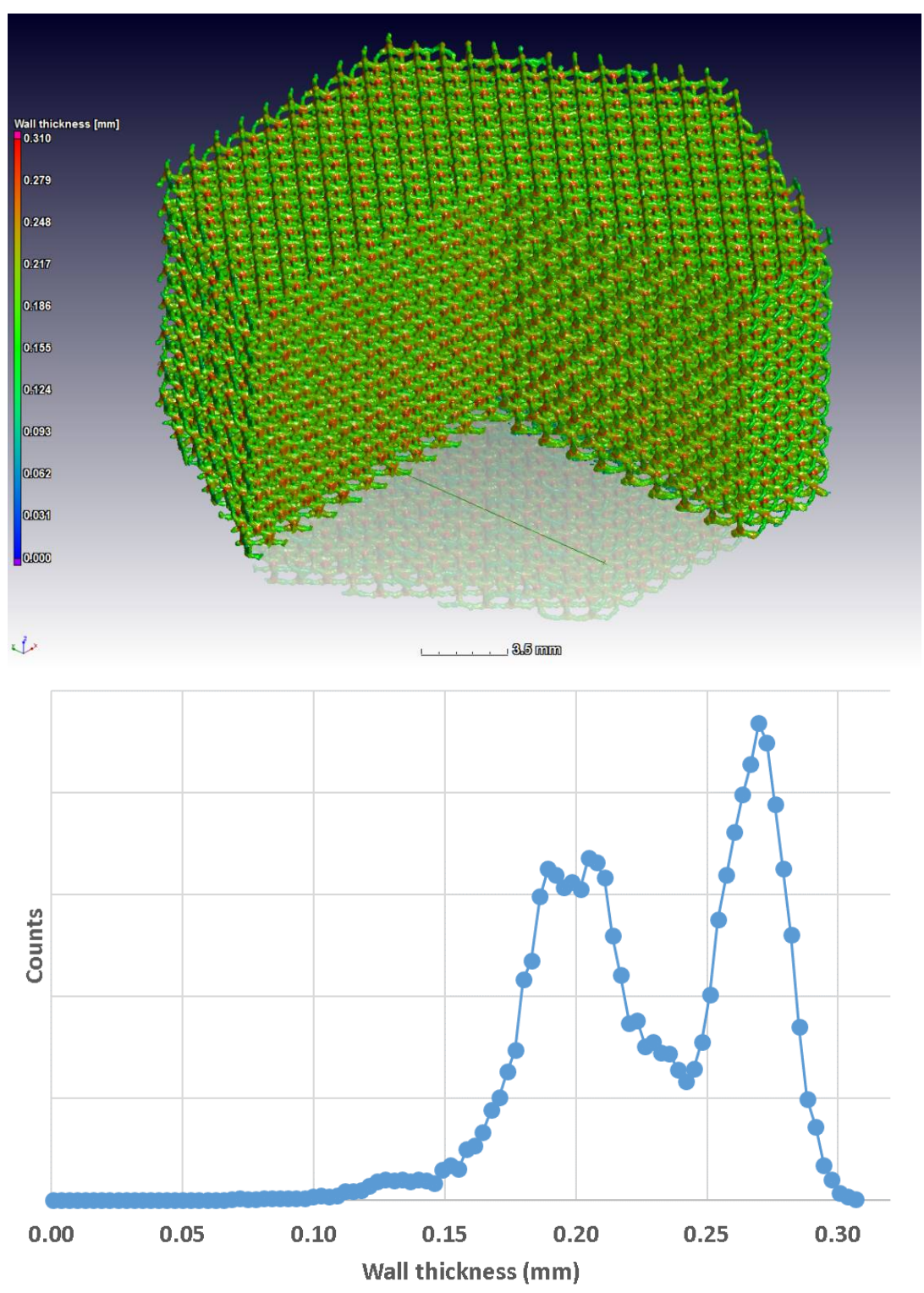

Figure 3: MicroCT analysis of wall thickness of produced biomimetic lattice sample (number 7), showing strut thickness 0.2 $\mathrm{mm}$ and joints $0.27 \mathrm{~mm}$.

Figure 4 shows the mechanical test results for the lattice-only model (sample number 7) to full densification. The initial yielding occurs at $12 \mathrm{kN}$. This is followed by the typical yield-recover cycles for layer-by-layer yielding of the lattice with a mean plateau force around $7 \mathrm{kN}$ (indicated in dashed line), before full densification. This typical response for lattice failure is useful for energy absorption and protection applications. 


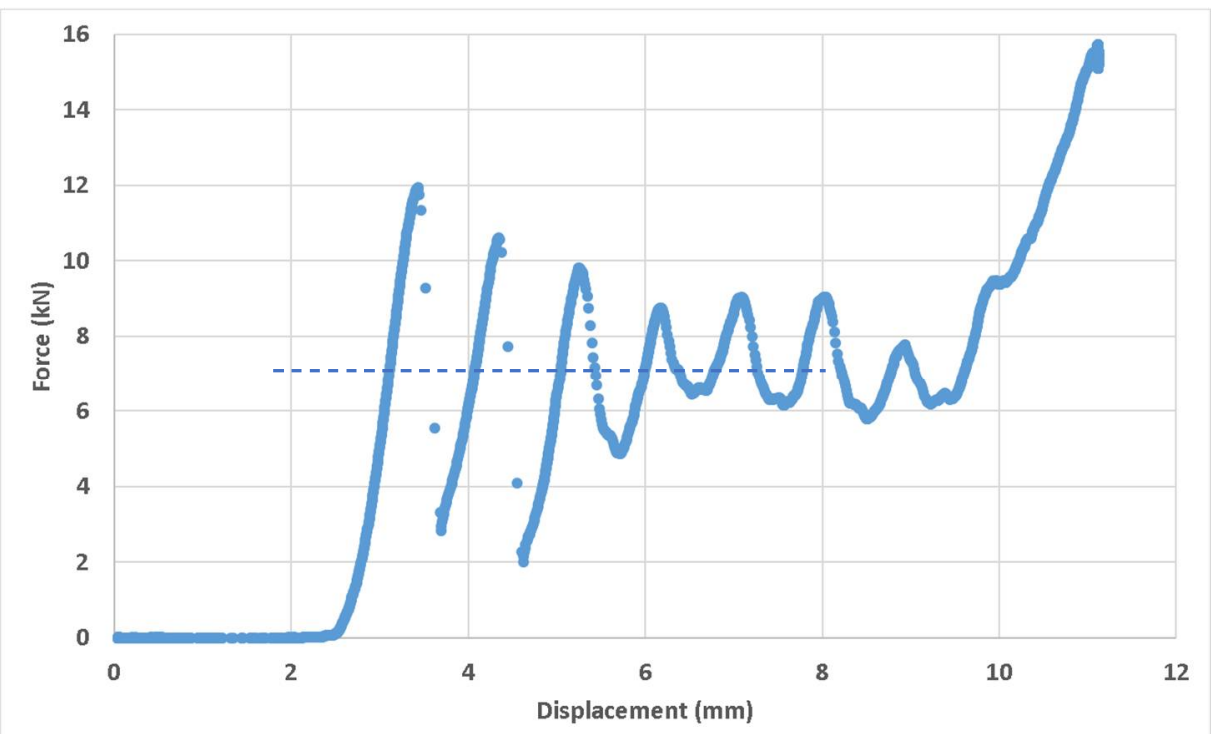

Figure 4: The static compression test of the weakest sample - the lattice-only design (sample 7) achieves yield force of 12 $\mathrm{kN}$ for $0.2 \mathrm{~mm}$ struts. Yielding plateau is indicated by dashed line, occurring at $7 \mathrm{kN}$.

In the biomimetic reference design, a solid shell is combined with an internal lattice. The lattice core provides impact protection as it fails incrementally and yielding takes place continuously until final densification, as explained above. The shell provides additional strength, making the initial yield force higher for increasing shell thickness as shown in Figure 5 for a series of samples with no shell, $0.5 \mathrm{~mm}$ shell and $1 \mathrm{~mm}$ shell. In this case the initial yielding takes place at 12,57 and $88 \mathrm{kN}$ respectively. However, the yielding after initial failure differs: in the case of the $0.5 \mathrm{~mm}$ shell, the recovery is reasonable, with a plateau at approximately $35 \mathrm{kN}$. For the $1 \mathrm{~mm}$ shell, the failure is more catastrophic, with the plateau after initial yielding below $10 \mathrm{kN}$. The sudden onset of initial failure creates damage to the internal lattice, removing its protective role, in the case of the thicker shell with very porous core. In this case, as the shell is made thicker, the lattice core is made more porous, hence having thinner struts.

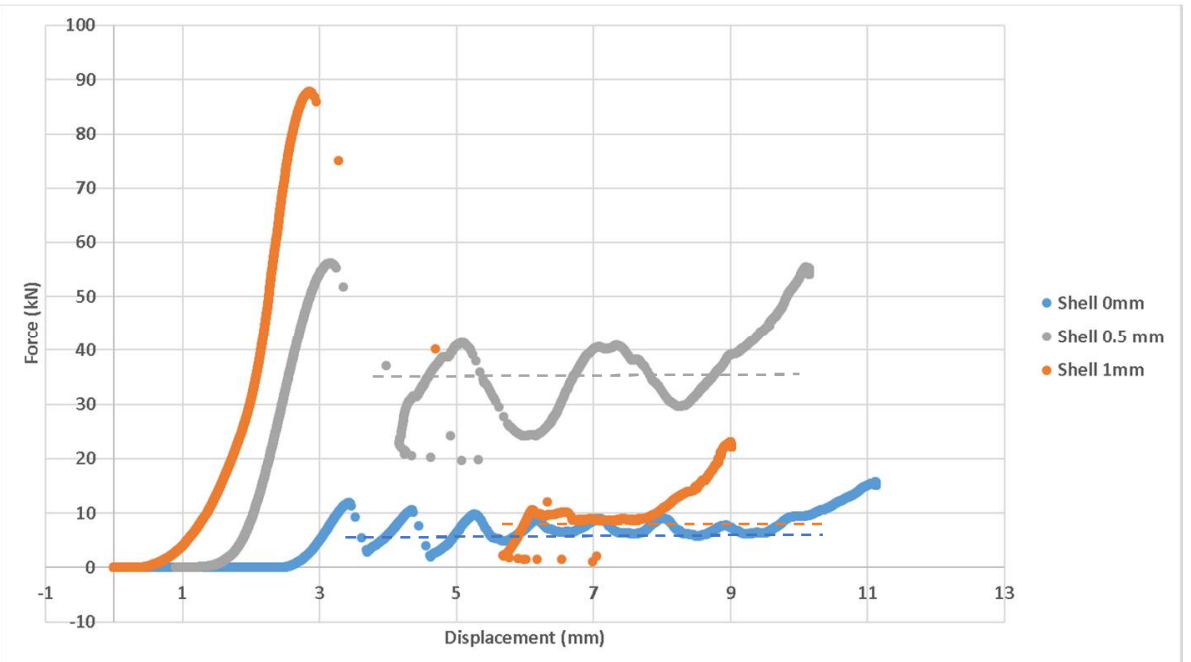

Figure 5: Shell provides increased strength prior to lattice collapse, but plateau varies.

The lattice core plays a role not only in the energy absorption and impact protection, but also a fundamental role in the system's initial yield strength, as seen in Figure 6 - for denser lattice core (with same shell thickness of $1 \mathrm{~mm}$ ), the strength is increased, and the plateau load is also increased. In this case the two denser models are significantly better for impact protection. The peak load of $180 \mathrm{kN}$ is also impressive, considering it maintains a high plateau and hence protective role as well. 


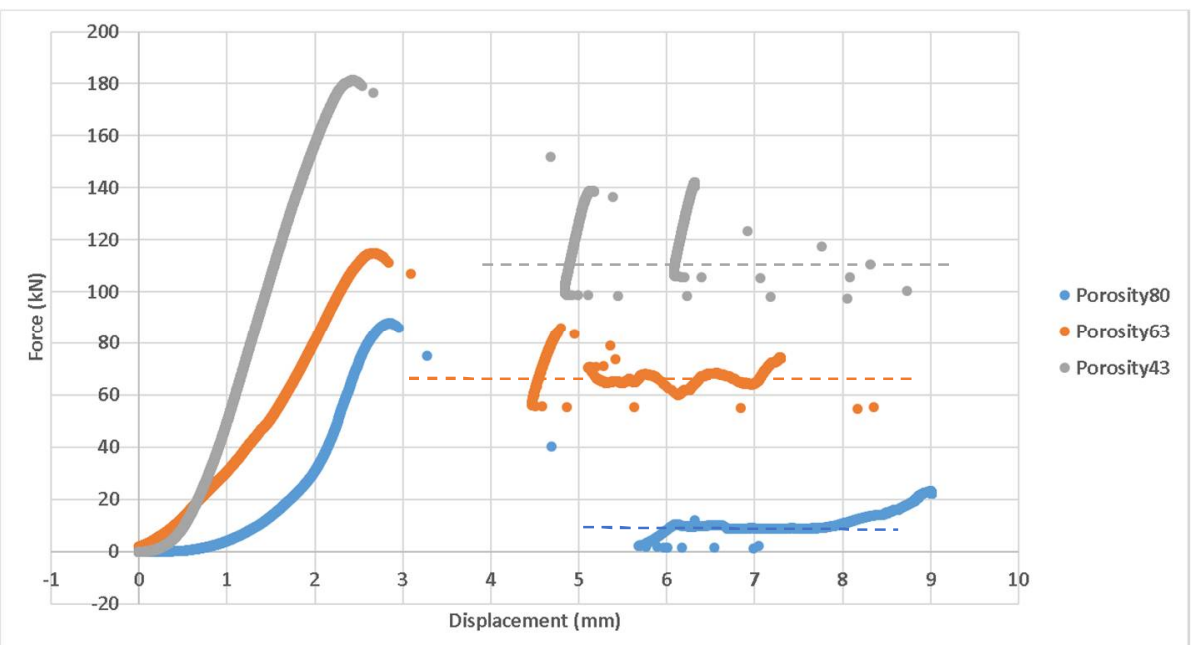

Figure 6: Denser lattice core provides stronger system, with peak failure load $180 \mathrm{kN}$.

Finally, Figure 7 shows the effect of a variation of unit cell size in the internal lattice. In all three cases the initial yielding is at $85-90 \mathrm{kN}$ indicating that this parameter does not affect the initial strength, as it is most affected by the shell thickness. In all three cases here the plateau recovery and energy absorption is low, indicating yielding causes damage to the lattice irrespective of the strut thickness.

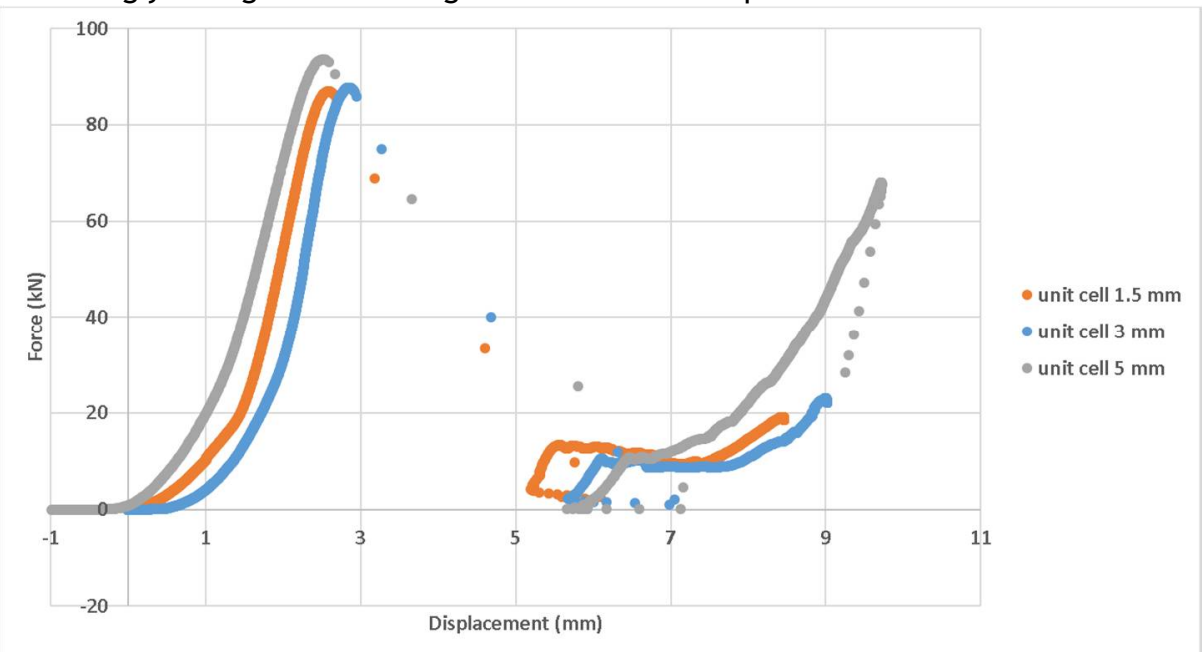

Figure 7: Effect of unit cell size - effectively strut thickness is varied while keeping porosity total constant. The strength is effectively identical, indicating that strut thickness (due to cell size change) does not play a significant role in the mechanical properties of a sample with relatively thick shell.

\section{CONCLUSIONS}

This work reports the first biomimetic study using metal additive manufacturing to date. In this work it was specifically shown that biomimetic impact protective samples could be manufactured by laser powder bed fusion in Ti6Al4V. Mechanical test results were reported and samples show good strength and energy absorption as indicated by the force-displacement curves. It was shown that the lattice-shell combinations can combine to create good strength and high energy absorption during yielding, to provide impact protective properties. However, when the shell becomes too thick relative to the lattice core, the onset of initial failure causes damage to the internal lattice, removing its protective role. Conversely, lack of shell provides little strength against damage and low energy absorption in total. There are therefore ideal combinations of shell thickness and lattice porosity. The results indicate that for the size and thickness of this biomimetic body armour unit in Ti6Al4V, a $0.5 \mathrm{~mm}$ shell with $80 \%$ porous lattice core provides a good response, or thicker shell $(1 \mathrm{~mm})$ with denser internal lattice $(60 \%$ or $40 \%$ porosity only) for higher strength and energy absorption.

\section{ACKNOWLEDGEMENTS}

We are very grateful for the excellent sample production at the Central University of Technology, especially Johan Els is thanked for his help in producing the models for this work. Funding from CPAM is hereby also acknowledged. 


\section{REFERENCES}

[1] J.M. Benyus, Biomimicry : innovation inspired by nature, Perennial, 2002. http://cds.cern.ch/record/1694347 (accessed June 13, 2018).

[2] J. Liu, A.T. Gaynor, S. Chen, Z. Kang, K. Suresh, A. Takezawa, L. Li, J. Kato, J. Tang, C.C.L. Wang, L. Cheng, X. Liang, A.C. To, Current and future trends in topology optimization for additive manufacturing, Struct. Multidiscip. Optim. (2018) 1-27. doi:10.1007/s00158-018-1994-3.

[3] T. Kamps, M. Gralow, G. Schlick, G. Reinhart, Systematic Biomimetic Part Design for Additive Manufacturing, Procedia CIRP. 65 (2017) 259-266. doi:10.1016/J.PROCIR.2017.04.054.

[4] A. du Plessis, C. Broeckhoven, I. Yadroitsev, I. Yadroitsava, S.G. le Roux, Analyzing nature's protective design: The glyptodont body armor, J. Mech. Behav. Biomed. Mater. 82 (2018). doi:10.1016/j.jmbbm.2018.03.037.

[5] A. du Plessis, C. Broeckhoven, A. Guelpa, S.G. le Roux, Laboratory x-ray micro-computed tomography: A user guideline for biological samples, Gigascience. (2017). doi:10.1093/gigascience/gix027.

[6] A. Du Plessis, C. Broeckhoven, S.G. Le Roux, Snake fangs: 3D morphological and mechanical analysis by microCT, simulation, and physical compression testing, Gigascience. 7 (2018) 1-8. doi:10.1093/gigascience/gix126.

[7] C. Broeckhoven, A. du Plessis, C. Hui, Functional trade-off between strength and thermal capacity of dermal armor: Insights from girdled lizards, J. Mech. Behav. Biomed. Mater. (2017). doi:10.1016/j.jmbbm.2017.06.007.

[8] J. Banhart, Manufacture, characterisation and application of cellular metals and metal foams, Prog. Mater. Sci. 46 (2001) 559-632. doi:10.1016/S0079-6425(00)00002-5.

[9] M. Ashby, T. Evans, N. Fleck, J. Hutchinson, Metal foams: a design guide, 2000. https: / / books.google.co.za/books?hl=en\&lr=\&id=COdalBo6LjgC\&oi=fnd\&pg=PP1\&ots=RzdRpOQWLh\&s ig=Qn3nc7WmcuuoFa7fl4QUxiACMHk (accessed May 15, 2018).

[10] A. du Plessis, S.G. le Roux, A. Guelpa, The CT Scanner Facility at Stellenbosch University: An open access X-ray computed tomography laboratory, Nucl. Instruments Methods Phys. Res. Sect. B Beam Interact. with Mater. Atoms. 384 (2016) 42-49. doi:10.1016/J.NIMB.2016.08.005.

[11] A. du Plessis, I. Yadroitsev, I. Yadroitsava, S.G. Le Roux, X-Ray Microcomputed Tomography in Additive Manufacturing: A Review of the Current Technology and Applications, 3D Print. Addit. Manuf. 0 (2018). doi:10.1089/3dp.2018.0060.

[12] I. Maskery, N.T. Aboulkhair, A.O. Aremu, C.J. Tuck, I.A. Ashcroft, Compressive failure modes and energy absorption in additively manufactured double gyroid lattices, Addit. Manuf. 16 (2017) 24-29. doi:10.1016/J.ADDMA.2017.04.003.

[13] Azom, Properties of Ti6Al4V, (n.d.). https://www.azom.com/article.aspx?ArticlelD=1547 (accessed September 17, 2018).

[14] A. Du Plessis, D.-P. Kouprianoff, I. Yadroitsava, I. Yadroitsev, A. Du Plessis, D.-P. Kouprianoff, I. Yadroitsava, I. Yadroitsev, Mechanical Properties and In Situ Deformation Imaging of Microlattices Manufactured by Laser Based Powder Bed Fusion, Mater. 2018, Vol. 11, Page 1663. 11 (2018) 1663. doi:10.3390/MA11091663. 